\title{
Prevalence and Predictors of Mental Illness Among Inmates in Northwestern Ethiopia: a New Look Into the Roles of Rehabilitation Service Use.
}

Yassin Mohammed Yesuf ( $\square$ yasspsycho@gmail.com )

Department of Psychology, CSSH, University of Gondar

\section{Amlaku Alemu Birhan}

Department of Social Anthropology, CSSH, University of Gondar

Addisu Gedlu Birara

Department of Social Anthropology, CSSH, University of Gondar

\section{Bewket Dereje Adimas}

Department of Criminology and Criminal Justice, CSSH, University of Gondar

Abebe Bahiru Bezabeh

Department of Law, School of Law, University of Gondar

\section{Nega Gedfaw Agmase}

Department of Criminology and Criminal Justice, CSSH, University of Gondar

\section{Research Article}

Keywords: Mental illness, inmates, prisons, rehabilitation services, Northwestern Ethiopia

Posted Date: February 16th, 2022

DOI: https://doi.org/10.21203/rs.3.rs-1315600/v1

License: (c) (i) This work is licensed under a Creative Commons Attribution 4.0 International License. Read Full License 


\section{Abstract}

\section{Background}

Data over the magnitude of mental illnesses and associated factors among inmates in Ethiopia in general and in Amhara region in particular are scares. The available studies either focused on specific type of mental illness or include inmates from a single correctional center and leave aside the role of rehabilitation service use in inmates' mental illness. Therefore, the present study was conducted to look into the prevalence of mental illnesses and to examine the associated demographic, imprisonment related and rehabilitation service use related factors that predict the mental illnesses of inmates in Northwestern Ethiopia.

\section{Methods}

The study employed cross-sectional, descriptive and explanatory research design where data was collected from 422 inmates from three randomly selected prisons. Inmates' mental illness was assessed using the Self Report Questionnaire (SQR-20). Frequency, percentage, bivariate and multiple logistic regressions were used to analyze the collected data.

\section{Results}

In the study it was revealed that $74.6 \%$ of the inmates in Northwestern Ethiopia have mental illnesses. Feeling unhappy, difficulty to play important role in life, headaches and bad sleep were experienced by majority of the respondents. Male inmates $(A O R=2.39,95 \% \mathrm{Cl}=1.07-5.37)$ and inmates who participate in the educational training services $(A O R=2.20,95 \% \mathrm{Cl}=1.36-3.55)$ were found to have higher chances of having mental illnesses. On the other hand, inmates who participate in life skill training programs $(A O R=0.45,95 \% \mathrm{Cl}=0.28-0.74)$ and inmates who participate in recreational and cultural activities $(\mathrm{AOR}=0.26,95 \% \mathrm{Cl}=0.14-0.46)$ were found to have lower odds of developing mental illnesses.

\section{Conclusion}

Higher prevalence of mental illnesses among inmates was found in Northwestern Ethiopia and inmates' participation in rehabilitation services were important predictors of their mental health. Thus prison administrators and policy makers need to initiate large scale studies thereby interventions that could reform the rehabilitation services provisions, including mental health services.

\section{Background}

Mental illness is now being recognized as a major public health problem throughout the world. Prevalence studies highlight the gravity of the problem and thereby challenge policy makers to take appropriate action. In Ethiopia mental illness comprised $11 \%$ of the total burden of disease and the disability associated with it is high (1). 
Although no population group is immune to mental illnesses, some population groups are at higher risks of developing mental illnesses. The prison populations are among the high risk group of population for developing mental illnesses. In reality inmates were found to have higher levels of mental illnesses than the general population $(2,3)$.

The high prevalence of mental illnesses in the prison population could be attributed to pre-prison situations and/or to the prison environment. On the one hand individuals with mental illnesses have higher chances of incarcerations for they are more likely to break the law (4). On the other hand the prison environment that is characterized by overcrowding, violence, isolations, etc. could increase the probability of inmates developing mental illnesses $(1,5,4)$.

Understanding the prevalence and associated factors of mental illnesses among prison inmates would help to provide targeted interventions and design appropriate health care services to the prison inmates $(4,6)$. Lack of such understanding could have dire consequences. Because inmates with mental illnesses are at higher risk of suicide, self-harm violence, victimization, premature death and reoffending $(2,4)$. Therefore, it is imperative to examine the prevalence and associated factors of mental illnesses among prison inmates.

In practice, studies over the mental illness levels of inmates reported different prevalence rates ranging from $86 \%$ in Southwestern Uganda (3) to $29.2 \%$ in Zambia (7). With regard to contributors a host of factors contributed to the high prevalence of mental illnesses among inmates. In resource poor countries like Ethiopia there are a host of factors that increased the risk of mental illness in prisons $(1,5)$.

While these are the facts on the ground studies over the mental illness prevalence and associated factors among inmates are scant in low and middle income countries $(8,3,9,10,7)$. Likewise, data over the magnitude of mental illnesses and associated factors among inmates in Ethiopia in general and in Amhara region in particular are scares $(6,11,5)$. The available studies either focused on specific type of mental illness or include inmates from a single correctional center. For example two studies in Northwestern Ethiopia focused on psychological distress (6) and anxiety (12) while a study on mental illnesses of inmates in Northwestern Ethiopia collected data from Debremarkos correctional institute only (13). The focus on specific mental illnesses and specific facility will not give proper insights about the total picture of the mental illness situations of inmates to policy makers and prison administrators. In addition the studies examined the associated demographic and prison related factors which leaves aside the roles of important factors like participation in the available rehabilitation services.

Mean a while studies in different corners of the globe have depicted rehabilitation service use related factors associated with mental illness of inmates. For instance participation in life skill training programs $(14,15)$ and involvement in recreational and cultural activities (16-18) were associated with inmates' mental illness.

Besides, the Ministry of Health considers the inadequate services in prisons, particularly the mental health service, as important factor that increased the risk of mental illnesses in prisons (1). Moreover, in a study 
in Northwestern Ethiopia it was depicted that low to no satisfaction with prison services significantly predicted inmates' psychological distress level (6). These all implied that there is a need to examine the associations of service use with mental illness among inmates.

In the present study we argued that inmates' participation in the rehabilitation services are associated with their mental illnesses. However, the association between prison rehabilitation service use and mental illnesses are least explored, at least to the knowledge of the present researchers. Hence, the present study was conducted to look into the prevalence of mental illnesses and to examine the associated demographic, imprisonment related and rehabilitation service use related factors that predict the mental illnesses of inmates in Northwestern Ethiopia. In doing so the findings of the present study will help policy makers and prison administration bodies to plan targeted interventions, hire more mental health prison staff members and reform mental health service provisions.

\section{Methods}

\section{Research Design}

Based on its data collection timing, the present study employed cross sectional research design where data were collected at a time from all the respondents. In terms of its methods of analysis, the study employed both descriptive and explanatory research designs. It is descriptive in that it summarized and described the characteristics of respondents and their mental illness levels. It is explanatory because it tests the causal relationships that exist between mental illness and predictor variables.

\section{Setting}

Amhara regional state hosts 31 correction facilities from which 30 of them are under the administrative jurisdiction of the region and one (Shewarobit Rehabilitation and Correction center) is that of the federal government. Correctional centers in the region are divided into two levels: (a) higher level (12 in number); and (b) medium and lower level (18 in number). Of the 30 prisons in Amhara National Regional State (excluding the center administered by the federal government) 10 of the prisons are found in the Northwestern part of the regional state. Simple random sampling technique was used to select three prisons: Gondar, Debretabor and Bahirdar prisons. Gondar and Bahirdar prisons are higher level correction centers while Debretabor correction center is included under lower and medium level centers. Based on the data collected from the three prisons there were 7164 prison inmates.

\section{Sample size}

For the purpose of determining the sample size of the study single proportion formula was used $(n=$ $\left.\left[Z^{2} a / 2 X p(q)\right] / d^{2}\right)$ with $95 \%$ confidence interval, a proportion of $50 \%(0.5)$ and $e= \pm 0.05$. Based on the computations using the formula the minimum sample size was 384 . Assuming $10 \%$ non-response rate the final sample size was 422 . Simple random sampling was used to select participants from each correction center. 


\section{Instrument}

In the present study data was collected using a structured and pretested questionnaire. The questionnaire has four sections. The first section collects data about inmates' demographic data (age, gender, educational status, religion, marital status and employment status before incarceration). The second section collects imprisonment related data that includes frequency of imprisonment, convict status, length of stay and types of crimes committed. The third section includes lists if rehabilitation services (guidance and counseling services; life skill training program; educational training; vocational training; work experience/employment services; medical services; library services; recreational and cultural services; psychiatry services; social relation with family; and substance abuse treatment). Then respondents were asked to indicate their participation in the listed services with "Yes, I participate" and "No, I don't participate" options.

The forth section of the questionnaire assess inmates' mental illness level. Inmates' mental illness was assessed using Self Report Questionnaire (SQR-20) developed by WHO to used in low income countries for assess mental illness symptoms (19). The SRQ was developed to assess 5 psychotic symptoms and 20 neurotic symptoms. The SRQ-20 which assessed 20 neurotic symptoms is used in the present study. Based on the user guide the inmates were presented with 20 statements and were asked to indicate if they have the typical symptom in the past month. They are also presented with Yes/No options and replying Yes (1) was considered as having the symptom while relying No (0) implying not having the symptom.

SRQ-20 has been used in prison settings in Africa. For example it has been used in Zambia with a cut off score of $\geq 8$ (7). It has also been used among inmates in Ethiopia with different cut off scores. For instance, it was used in Debremarkos with a cutoff scores of $>=6$ (13) while a study in Addis Ababa (10) and a study in Jimma correctional institute (9) used a cut off score of 8 . In the present study a cut off score of 8 was used to categorize an inmate as having mental illness.

\section{Data collection procedure}

The questionnaire was translated to Amharic by a psychologist and language experts. It was then back translated by other psychologists and language experts who were not familiar with the purpose of the study. And minor differences in translations were resolved through a focus-group discussion. Data collection process was carried out by six trained M.A. holders. Before data entry, collected data was examined and validated for completeness, and incomplete data was eliminated.

\section{Data analysis}

Both descriptive and inferential statistics were used in the present study. Frequencies and percentages were computed to describe respondents' demographic, imprisonment related and rehabilitation service use related characteristics. Frequencies and percentages were also employed to describe prevalence of mental illnesses among inmates. To examine association between mental illness and the associated factors, bivariate and multivariate logistic regression models were used. The statistical significance of 
mental illness and associated factors was determined using an adjusted odds ratio with a 95 percent confidence interval. All data analyses were carried out using SPSS version 23.

\section{Results}

\section{Demographic descriptions of the respondents}

As can be seen from Table 1 majority of the respondents are young aged between 18 and 40 years (74.2\%), are males (92.2\%), attend secondary education (39.3\%), are Orthodox Christians (96\%), are married (48.6\%) and are employed (42.7\%).

Table 1: Demographic characteristics of the respondents $(N=422)$

\begin{tabular}{|c|c|c|c|}
\hline Variables & Category & Frequency & Percentage \\
\hline \multirow[t]{3}{*}{ Age } & $18-40$ & 333 & 78.9 \\
\hline & $41-60$ & 83 & 19.7 \\
\hline & $>60$ & 6 & 1.4 \\
\hline \multirow[t]{2}{*}{ Gender } & Male & 389 & 92.2 \\
\hline & Female & 33 & 7.8 \\
\hline \multirow[t]{5}{*}{ Educational Status } & No education & 47 & 11.1 \\
\hline & Primary Education & 147 & 34.8 \\
\hline & Secondary Education & 166 & 39.3 \\
\hline & Diploma & 28 & 6.6 \\
\hline & Others & 34 & 8.1 \\
\hline \multirow[t]{2}{*}{ Religion } & Orthodox & 405 & 96.0 \\
\hline & Muslim & 17 & 4.0 \\
\hline \multirow[t]{3}{*}{ Marital Status } & Single & 195 & 46.2 \\
\hline & Married & 205 & 48.6 \\
\hline & Divorced & 22 & 5.2 \\
\hline \multirow[t]{3}{*}{ Employment Status } & Unemployed & 63 & 14.9 \\
\hline & Employed & 180 & 42.7 \\
\hline & Self-employed & 179 & 42.4 \\
\hline
\end{tabular}




\section{Imprisonment related characteristics of the respondents}

Imprisonment related characteristics of the respondents are presented in Table 2. Majority of the respondents are imprisoned once (95.7\%), have convicted status (85.5\%), stay in the prison between 1 and 5 years $(67.8 \%)$ and committed crimes against person $(57.8 \%)$.

Table 2: Imprisonment characteristics of the respondents $(\mathrm{N}=422)$

\begin{tabular}{|c|c|c|c|}
\hline Variables & Category & Frequency & Percentage \\
\hline \multirow[t]{3}{*}{ Frequency of imprisonment } & First time & 404 & 95.7 \\
\hline & Second time & 8 & 1.9 \\
\hline & Third time & 10 & 2.4 \\
\hline \multirow[t]{3}{*}{ Convict status } & Pre trail & 23 & 5.5 \\
\hline & Accused & 38 & 9.0 \\
\hline & Convicted & 361 & 85.5 \\
\hline \multirow[t]{3}{*}{ Length of Stay } & $>1$ year & 120 & 28.4 \\
\hline & $1-5$ years & 286 & 67.8 \\
\hline & $>6$ years & 16 & 3.8 \\
\hline \multirow[t]{3}{*}{ Types of Crime } & Crime Against Person & 244 & 57.8 \\
\hline & Crime against Property & 123 & 29.1 \\
\hline & Crime Against State & 55 & 13.0 \\
\hline
\end{tabular}

\section{Inmates' participation at rehabilitation services}

Inmates' participation in the available rehabilitation services are presented in Table 3. Of the available services in the prisons, higher number of inmates participates in guidance and counseling service (66.1\%); educational trainings (51.7\%); vocational trainings (58.8\%); work experience/employment services (54.3\%); medical services (72.5\%); and social relations with family (89.1\%). Lower levels of participation was found at life skill training program (30.1\%); library services (41.7\%); recreational and cultural activities (14.9\%); psychiatry services (13.3\%); and substance abuse treatment (10.4\%).

Table 3: Respondents' rehabilitation service use status $(\mathrm{N}=422)$ 


\begin{tabular}{|c|c|c|c|}
\hline Variables & Category & Frequency & Percentage \\
\hline \multirow[t]{2}{*}{ Guidance and counseling Service } & Use & 279 & 66.1 \\
\hline & Don't Use & 143 & 33.9 \\
\hline \multirow[t]{2}{*}{ Life skill training program } & Use & 127 & 30.1 \\
\hline & Don't Use & 295 & 69.9 \\
\hline \multirow[t]{2}{*}{ Educational training } & Use & 218 & 51.7 \\
\hline & Don't Use & 204 & 48.3 \\
\hline \multirow[t]{2}{*}{ Vocational training } & Use & 246 & 58.3 \\
\hline & Don't Use & 176 & 41.7 \\
\hline \multirow[t]{2}{*}{ Work experience/employment services } & Use & 229 & 54.3 \\
\hline & Don't Use & 193 & 45.7 \\
\hline \multirow[t]{2}{*}{ Medical service } & Use & 306 & 72.5 \\
\hline & Don't Use & 116 & 27.5 \\
\hline \multirow[t]{2}{*}{ Library Services } & Use & 176 & 41.7 \\
\hline & Don't Use & 246 & 58.3 \\
\hline \multirow[t]{2}{*}{ Recreational and cultural activities } & Use & 63 & 14.9 \\
\hline & Don't Use & 359 & 85.1 \\
\hline \multirow[t]{2}{*}{ Psychiatry Services } & Use & 56 & 13.3 \\
\hline & Don't Use & 366 & 86.7 \\
\hline \multirow[t]{2}{*}{ Social relation with family } & Use & 376 & 89.1 \\
\hline & Don't Use & 46 & 10.9 \\
\hline \multirow[t]{2}{*}{ Substance abuse treatment } & Use & 44 & 10.4 \\
\hline & Don't Use & 378 & 89.6 \\
\hline
\end{tabular}

\section{Prevalence of mental illness among inmates}

Of all the participants of the study $74.6 \%$ of them (374 in numbers) were found to have mental illnesses. Besides, feeling unhappy (308 inmates), unable to play useful part in life (286 inmates), head ache (282 inmates) and sleep badly (282 inmates) were symptoms reported by high number of inmates. On the other hand handshakes, suicidal thoughts and crying more than usual were symptoms experienced by lower numbers of inmates reported by 114, 115 and 145 inmates, respectively (see Fig. 1). 


\section{Factors associated with mental illness}

In the bivariate analysis gender, length of stay, participation in life skill training program, use of educational training services and involvement in recreational and cultural activities were found to be significantly associated with inmates' mental illness.

In the multiple logistic regression analysis all these variables, except length of stay in the prison, remained significant. In Table 4 variables which were significant in the bivariate analysis are included and data for other variables are not included (see Additional File 1). Specifically it was found that males were 2.39 times more likely to have mental illnesses $(A O R=2.39,95 \% \mathrm{Cl}=1.07-5.37)$ than female inmates. In terms of rehabilitation service use, inmates who participate in life skill training programs were found to have lower chances of developing mental illnesses ( $A O R=0.45,95 \% \mathrm{Cl}=0.28-0.74$ ) than inmates who don't participate in life skill training programs. However, inmates who participate in the educational training services were found to have higher odds of having mental illnesses $(A O R=2.20,95 \% \mathrm{Cl}=1.36-$ 3.55) than inmates who don't participate in the educational training services. On the other hand the odds of inmates developing mental illnesses were found to be lower for inmates who participate in recreational and cultural activities $(\mathrm{AOR}=0.26,95 \% \mathrm{Cl}=0.14-0.46)$ than the inmates who don't participate in these activities.

Table 4: Bivariate and Multivariate logistic regression results of predictor variable 


\begin{tabular}{|c|c|c|c|c|c|c|c|}
\hline \multirow[t]{2}{*}{ Variable } & \multirow[t]{2}{*}{ Category } & \multicolumn{2}{|c|}{$\begin{array}{l}\text { Mental } \\
\text { illness }\end{array}$} & \multirow[t]{2}{*}{$\mathrm{OR}(\mathrm{Cl})$} & \multirow[t]{2}{*}{$\mathrm{p}$} & \multirow[t]{2}{*}{$\mathrm{AOR}(\mathrm{Cl})$} & \multirow[t]{2}{*}{$\mathrm{p}$} \\
\hline & & No & Yes & & & & \\
\hline \multirow[t]{2}{*}{ Gender } & Male & 91 & 298 & $\begin{array}{l}3.08(1.50 \\
6.34)\end{array}$ & .002 & $\begin{array}{l}\text { 2.39 (1.07, } \\
5.37)\end{array}$ & .035 \\
\hline & Female & 16 & 17 & 1 & & & \\
\hline \multirow[t]{3}{*}{ Length of Stay } & $>1$ year & 38 & 82 & $\begin{array}{l}1.66(1.08 \\
2.54)\end{array}$ & .021 & $\begin{array}{l}.17(.02 \\
1.42)\end{array}$ & .102 \\
\hline & $\begin{array}{l}1-5 \\
\text { years }\end{array}$ & 68 & 218 & $\begin{array}{l}.14(.02, \\
1.13)\end{array}$ & .065 & $\begin{array}{l}.20(.02 \\
1.57)\end{array}$ & .124 \\
\hline & $>6$ years & 1 & 15 & 1 & & & \\
\hline \multirow[t]{2}{*}{ Life skill training program } & Use & 45 & 82 & $.49(.31, .77)$ & .002 & $\begin{array}{l}.45(.28, \\
.74)\end{array}$ & .002 \\
\hline & $\begin{array}{l}\text { Don't } \\
\text { Use }\end{array}$ & 62 & 233 & 1 & & & \\
\hline \multirow[t]{2}{*}{ Educational training } & Use & 44 & 174 & $\begin{array}{l}1.77(1.13, \\
2.76)\end{array}$ & .012 & $\begin{array}{l}2.20(1.36 \\
3.55)\end{array}$ & .001 \\
\hline & $\begin{array}{l}\text { Don't } \\
\text { Use }\end{array}$ & 63 & 141 & 1 & & & \\
\hline \multirow{2}{*}{$\begin{array}{l}\text { Recreational and cultural } \\
\text { activities }\end{array}$} & Use & 32 & 31 & $.26(.15, .45)$ & .000 & $26(.14, .46)$ & .000 \\
\hline & $\begin{array}{l}\text { Don't } \\
\text { Use }\end{array}$ & 75 & 284 & 1 & & & \\
\hline
\end{tabular}

\section{Discussions}

The present study explored the prevalence and predictors of mental illness among inmates in Northwestern Ethiopia. This study is one of its kinds in the sense that it considers rehabilitation service use as predictors of mental illness alongside demographic and imprisonment related factors.

In the present study it was revealed that about two third of the inmates in Northwestern Ethiopia have mental illnesses. A similar mental illness prevalence rate was reported in Iran where a prevalence rate of $73.9 \%$ was reported among prisoners (20).

Slightly lower prevalent rates of mental illness among inmates were reported in Ethiopia and other African countries. The prevalence of mental illness among prisoners in Debremarkos correctional institute was found to be $67.6 \%$ (13) slightly lower than the prevalence rate in the present study. The prevalence rate of mental illnesses among inmates in Addis Ababa was $58.4 \%$ (10). The prevalence rate of mental illnesses in Jimma correctional institute was $62.7 \%$ (9). A $63.2 \%$ prevalence rate of mental illness was reported among inmates from a study in Kenya (4). In a systematic review among studies in Africa the 
pooled prevalence of mental illnesses among adults is $59 \%$ while it is $61 \%$ among the youth (8). Methodological differences and the characteristics of the respondents included in the studies are behind the differences in findings. For example in the study in Addis Ababa half of the respondents (50.1\%) are females while only $7.8 \%$ of the participants in our study are female inmates.

Higher prevalence rates of mental illnesses among prisoners than the prevalence rate in the present study was reported in other studies. For instance, in a study in Southwestern Uganda mental illness was observed in $86 \%$ of the inmates (3). Likewise, a study in India reported a mental illness prevalence rate of $83.5 \%$ (21). Psychological distress was identified among $83.4 \%$ of inmates among prisons in Northwestern Ethiopia (6). The differences in findings are attributed to the tools used to measure mental illnesses. The studies in Southern Uganda and India used Mini-International Neuropsychiatric Interview (M.I.N.I.) that measured the prevalence of psychotic disorders while the study in Northwestern Ethiopia employed K10 that examined psychological distress.

Significantly lower mental illness prevalence rates are also reported in other African countries. The prevalence of mental illness rate reported in Zambia is $29.2 \%$ (7). Similarly, a mental disorder prevalence rate of $34.8 \%$ was reported from a study in a correctional prison in Yaoundè, Cameron (22). The differences are attributed to differences in the settings the data is collected and the tools used to assess mental illness. For example the study in Zambia is conducted in maximum security prisons among remanded, sentenced, and condemned inmates. Besides, the study in Cameron used M.I.N.I. to assess mental illness while our study employed SRQ-20.

Alongside to reporting the prevalence of mental illness, the present study depicted the most and the list reported mental illness symptoms by inmates. Feeling unhappy, difficulty to play important role in life, headaches and bad sleep were experienced by majority of the respondents. These symptoms were reported as high in the study among prisoners in Jimma correctional institute, southwestern Ethiopia (9). Handshakes, suicidal thoughts and crying more than usual were the symptoms least reported by inmates in the present study. These symptoms are also among the least reported symptoms in the study in Southwestern Ethiopia (9)(Adraro et al., 2019). These all could imply that the typical symptoms experienced by inmates are similar in different corners of the country.

Of all demographic variables considered, gender as an important predictor for inmates' mental illness was found in the present study. Unlike the findings from other studies, the present study found that male inmates have higher odds of having mental illness than their female counter parts.

Contrary to our findings the study at Debremarkos Correctional institute found that female inmates have higher probability of having mental illness than male inmates (13). In a study in Bonga town correction center female inmates were found to feel worthless and nervous than male inmates (23). Similarly in the study in Kenya female inmates were found to have higher chances of having mental illnesses than male inmates (4). The difference in the findings could be attributed to the high number of male inmates $(92.2 \%)$ included in our study. 
The present study highlights the important predictive effects of rehabilitation service use over inmates' mental illness. Of the 11 rehabilitation service use related variables considered in the study three of them were found to be important predictors of inmates' mental illness: life skill training program; educational training; and recreational and cultural activities.

In the present study inmates who participated in the life skill training programs were found to have lesser chances of developing mental illness. Likewise, in a study in Iran the mental health of women inmates who participated in anger management trainings were improved after the training (14) indicating the importance of life skill trainings. Another study in Iran found that inmates who participated in life skill trainings were found to have higher scores in positive mental adjustment (measured by assertiveness and self-esteem) and lower score in negative adjustment (measured by anxiety, depression, stress and aggressiveness) (15).

Participation in recreational and cultural activities are found to have a buffering effect against mental illness among prisoners. In line with our finding participation in recreational and cultural sport activities were reported as buffering against mental illnesses among inmates. For example in a study in the USA inmates who participated in group activities were found to have lower chances of experiencing anxiety. On the contrary the study depicted that being idle is associated with higher odds of anxiety and depression implying the importance of participation as a buffering against mental illnesses (17). In a study in Nigeria, inmates who participated in sport activities have better psychological and social wellbeing than inmates who don't participate (16). Likewise in a qualitative study in Northern Ireland it was depicted that participation in sport activities increases social interaction thereby improves inmates' psychological wellbeing (18).

Surprisingly, in the present study, participation in educational training services was found to predict higher chances of having mental illness among inmates. In the literature participation in prison educational programs was associated with lower recidivism, higher employment chances after release, reduced misconduct while in prison and strong return on investment (24). Findings of the present study associates prison education with increased mental illnesses. This could be potentially attributed to the many challenges associated to prison education in Africa, for example in South Africa (25) or the low quality and relevance of the educational service provisions reported among prisons in Amhara National Regional State (26) or other additional covariates that need further investigations.

The cross-sectional nature of the present study is considered as the first limitation of the study. Moreover, the numbers of female respondents in the present study are small in that it would be difficult to generalize the results to female inmates in the region. In addition, mental illness is not clinically diagnosed with trained professionals and there could be recall bias and/or over reporting of symptoms.

\section{Conclusions}

Higher prevalence of mental illnesses among inmates were found in Northwestern Ethiopia. Besides, inmates' participation in rehabilitation services were important predictors of their mental health. The 
higher rates of mental illness among the inmates calls up on an urgent intervention and prison mental health service reform to satisfy inmates mental health needs. Prison administrators, policy makers at both regional and national levels, ministry of justice, ministry of health and non-government organizations need to come together, discuss on potential immediate interventions and implement the interventions so as to combat the potential consequences of having such a huge number of inmates with mental illness in our prisons. Furthermore, the quality of the rehabilitation services rendered to the inmates need to be properly examined thereby appropriate measures need to be in place by concerned bodies.

Issues surrounding inmates' mental health, including prevalence, types and services that targeted mental illness, among other things are untapped research area for future researches. The role rehabilitation service use played against/towards inmates' mental illness need detailed, potentially longitudinal, studies at a wider scale.

\section{Declarations}

\section{Ethical approval Consent to participate}

This study is part of a mega-project and approval to conduct the study is secured after the protocol undergone through rigorous ethical examination by the college of social science and humanities research approval committee of UoG. The study is, hence, executed in accordance with relevant ethical guidelines and regulations. Formal letters directed to the selected facilities were written from the college of social science and humanities requesting permission to collect data at the respective facility. While delivering the letters, the purpose of the research was vividly communicated to prison administrators. At individual participant level the participants were informed about the purpose of the study and they were ensured that the information they would give will be used for the research purpose only. Measures were taken to maintain the respect, dignity and freedom of each individual participant and every inmate was assured about confidentiality. Participants were also ensured that they have full right to discontinued or refused to participate in the study. Statements that address these issues are included in the front page of each questionnaire. Besides, respondents were given the questionnaire after getting verbal consent from each of the respondents was secured. Finally the respondents sign the consent form before they begin filling the questionnaire.

\section{Consent for publication}

Not applicable.

\section{Availability of data and materials}

This study is part of a mega-research project and data sets used in the study will be available publicly as soon as all the data (including the qualitative data) is fully analyzed. For the time being the data sets 
used and/or analyzed during the current study are available from the corresponding author on reasonable request.

\section{Competing Interests}

The authors declare that they have no competing interests.

\section{Funding}

This research was conducted through financial support from University of Gondar. The funding body has no role in the design of the study and collection, analysis, and interpretation of data and in writing the manuscript.

\section{Authors' Contributions}

YM, AA and BD conceived the study and developed the tool. AA, BD, AB and NG collect the data. YM and $A A$ analyzed the data. $Y M, A A$ and $A G$ discussed the findings. $Y M, A A, A B$ and $N G$ developed the manuscript. All the authors have read and approved the final manuscript.

\section{Acknowledgements}

The authors would like to thank the prison administrators in the three facilities who helped us in collecting the data. We also want to thank the research participants for taking their time to fill the questionnaire.

\section{References}

1. MoH. National Mental Health Strategy (2012/13-2015/16) [Internet]. Addis Ababa: Federal Democratic Republic of Ethiopia Ministry of Health; 2012. Available from: https://www.mhinnovation.net/sites/default/files/downloads/innovation/reports/ETHIOPIANATIONAL-MENTAL-HEALTH-STRATEGY-2012-1.pdf

2. Fazel S, Hayes AJ, Bartellas $\mathrm{K}$, Clerici M, Trestman R. Mental health of prisoners: prevalence, adverse outcomes, and interventions. Lancet Psychiatry. 2016 Sep;3(9):871-81.

3. Forry JB, Ashaba S, Rukundo GZ. Prevalence and associated factors of mental disorders among prisoners in Mbarara municipality, southwestern Uganda: a cross-sectional study. BMC Psychiatry. 2019 Jun 11;19(1):178.

4. Museve JL, Angira CHO, Aloka PJ. Prevalence and associated factors of mental disorders among prisoners in Kenya. Int J Health Sci Res. 2020;10(7):261- 271.

5. Habtamu S. The Impact of Prison's Social Environment on Mental Health among Prisoners in East Gojjam Zone Correctional Centers, North-West Ethiopia. Int J Sci Eng Res. 2020;11(9):676-88.

6. Dachew BA, Fekadu A, Kisi T, Yigzaw N, Bisetegn TA. Psychological distress and associated factors among prisoners in North West Ethiopia: cross-sectional study. Int J Ment Health Syst. 2015 Dec 
$30 ; 9(1): 39$.

7. Mweene MN, Siziya S. Prevalence of mental illness among inmates at Mukobeko maximum security prison in Zambia: A cross-sectional study. J Ment Health Hum Behav. 2016 Jan 1;21:105.

8. Lovett A, Kwon HR, Kidia K, Machando D, Crooks M, Fricchione G, et al. Mental health of people detained within the justice system in Africa: systematic review and meta-analysis. Int J Ment Health Syst. 2019 May 6;13(1):31.

9. Adraro W, Kerebih H, Tesema W, Abamecha F, Hailesilassie H. Nearly three in every five prisoners experience common mental disorders (CMDs) in Jimma correctional institution; south-West Ethiopia. BMC Public Health. 2019 Nov 26;19(1):1559.

10. Solomon A, Mihretie G, Tesfaw G. The prevalence and correlates of common mental disorders among prisoners in Addis Ababa: an institution based cross-sectional study. BMC Res Notes. 2019 Jul 12;12(1):394.

11. Beyen TK, Dadi AF, Dachew BA, Muluneh NY, Bisetegn TA. More than eight in every nineteen inmates were living with depression at prisons of Northwest Amhara Regional State, Ethiopia, a cross sectional study design. BMC Psychiatry. 2017 Jan 19;17(1):31.

12. Dadi AF, Dachew BA, Kisi T, Yigzaw N, Azale T. Anxiety and associated factors among prisoners in North West of Amhara Regional State, Ethiopia. BMC Psychiatry. 2016 Mar 31;16(1):83.

13. Ali Y, Yigzaw N, Bekana L, Mekonen S. Prevalence of Common Mental Disorders and Associated Factors among Prisoners in Debre Markos Town Correctional Institution, North-West, Ethiopia. Int J Ment Health Psychiatry. 2016;2(2).

14. Bahrami E, Mazaheri Maryam Amidi, Hasanzadeh A. Effect of anger management education on mental health and aggression of prisoner women. J Educ Health Promot. 2016;5(5).

15. Hashemi L, Ahmadi A, Koushesh Z. Effectiveness of life skill training on prisoners' mental adjustment. Reef Resour Assess Manag Tech Pap. 2014;40(3):560-5.

16. Obadiora $\mathrm{AH}$. The influence of sport participation on quality of life perceptions among inmates in Nigerian prisons. J Sport Dev. 2016;4(6):36-43.

17. Vuk M. Inmate Time Utilization And Well-Being [Internet]. University of South Carolina; 2017. Available from: https://scholarcommons.sc.edu/etd/4061

18. Woods D, Hassan D, Breslin G. Positive collateral damage or purposeful design: How sport-based interventions impact the psychological well-being of people in prison. Ment Health Phys Act. 2017 Oct 1;13:152-62.

19. WHO. A User's guide to the self reporting questionnaire (SRQ / compiled by M. Beusenberg and J. Orley. 1994;(WHO/MNH/PSF/94.8. Unpublished). Available from: https://apps.who.int/iris/handle/10665/61113

20. Al-Abbudi S, Hashi M. Pattern of Psychiatric Morbidity and Substance Abuse among Iraqi Prisoners. J Addict Res [Internet]. 2019 Feb 8;3(1). Available from: https://www.researchgate.net/publication/330971770 
21. Tirumani SR, Vennam BSV, Seepana R. A study on prevalence of psychiatric morbidity and substance abuse among prisoners. Open J Psychiatry Allied Sci. 2020;11(2):96-9.

22. Nkoagne ECL, Yongsi HBN. Ending up in prison healthy and getting out mentally ill: Prevalence and risk factors of psychiatric illnesses among jail inmates at the Kondengui Central Prison (YaoundéCameroon). J Ment Health Hum Behav. 2018;23(1):43-51.

23. Roba G, Worku B. Symptoms and Underlying Factors of Psychological Distress among Inmates in Bonga Town Correctional Center. Int J Multicult Multireligious Underst. 2019 Jun 30;5:197-205.

24. Duwe G. The Effectiveness of Education and Employment Programming for Prisoner [Internet]. American Enterprise Institute.; 2018. Available from: https://files.eric.ed.gov/fulltext/ED585975.pdf

25. Khoabane MS. Challenges faced by incarcerated learners when progressing from Adult Education and Training level 4 to Grade 10 [Internet]. University of Pretoria; 2018. Available from: http://hdl.handle.net/2263/70122

26. Kabeta GG. Assessing the practices of prison education in selected prisons of Amhara National Regional State, Ethiopia [Internet]. University of South Africa; 2017. Available from: http://hdl.handle.net/10500/23166

\section{Figures}

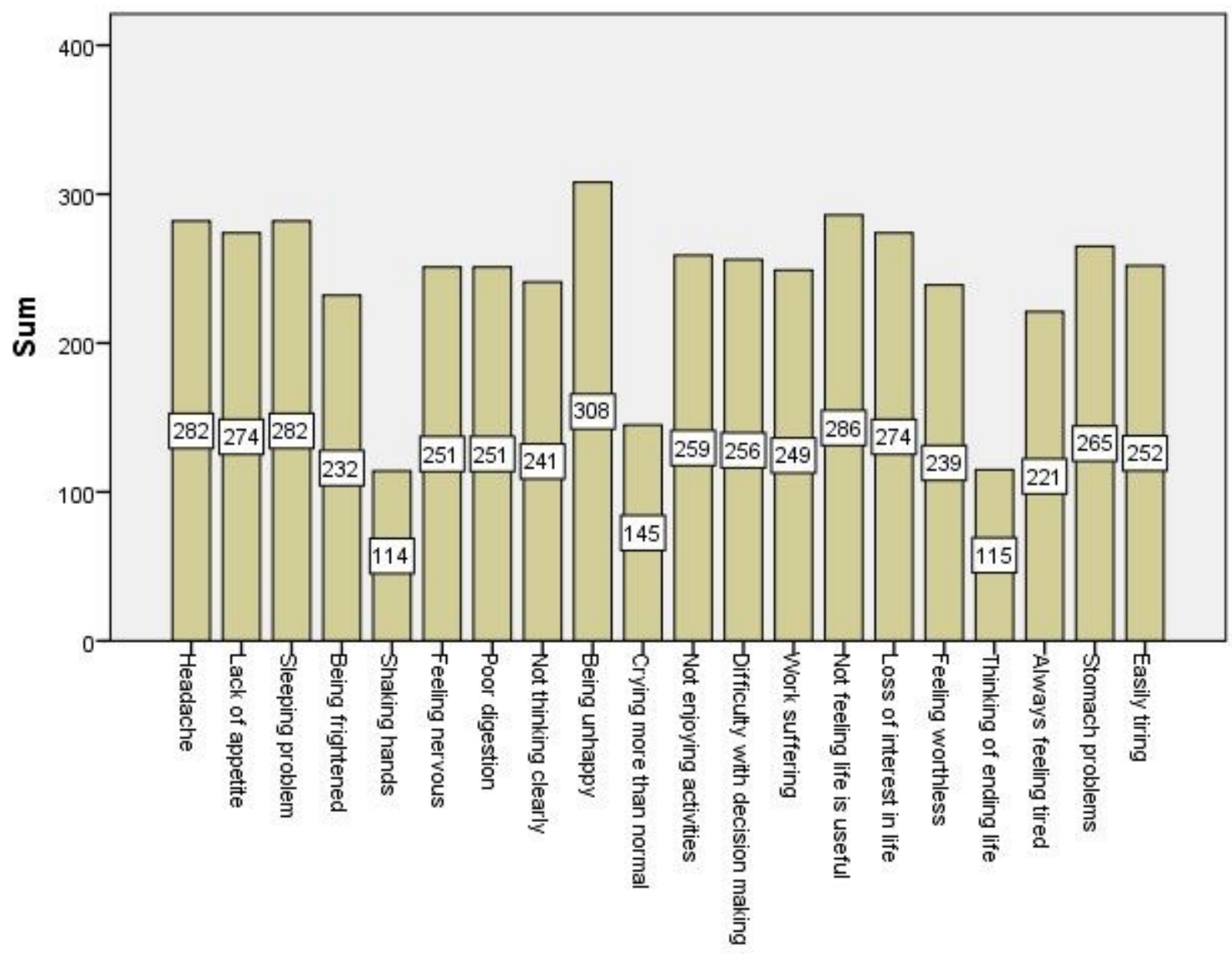

Figure 1: Frequency of reported mental illness symptoms 


\section{Figure 1}

See image above for figure legend.

\section{Supplementary Files}

This is a list of supplementary files associated with this preprint. Click to download.

- AdditionalFile1.doc 